\title{
Jejunal Web
}

National Cancer Institute

\section{Source}

National Cancer Institute. Lejunal Web. NCI Thesaurus. Code C98966.

The formation of tissue in the lumen of the jejunum that results in partial obstruction. 